\section{MRS Bulletin names Ilic as Postdoctoral Publication Prize recipient}

\author{
mrs.org/bulletin-prize
}

$\mathrm{T}^{\mathrm{s}}$ he MRS Bulletin has named Ognjen Ilic as the 2019 MRS Bulletin Postdoctoral Publication Prize recipient. This award recognizes postdoctoral researchers for their intellectual merit, the impact of their research and scholarship, and their interest in science writing and communications.

Ognjen was selected from dozens of well-qualified applicants and nominations for "his outstanding academic achievements, high quality of scientific publications, demonstrated passion for science communication, science outreach efforts to the general public, and clear potential to become a leader in the field of materials research." The award was presented at the 2019 MRS Fall Meeting in Boston.

Ognjen worked as a postdoctoral research associate from 2016 to 2019 in the Department of Applied Physics and Materials Science at the California Institute of Technology. He was recently appointed to the position of assistant professor at the University of Minnesota. He earned his $\mathrm{PhD}$ degree in physics in 2015 at the Massachusetts Institute of Technology. He was the Whiteman Fellow, Herchel Smith Research Fellow, and the Harvard College Research Program Fellow.

His research interests include nanophotonics, heat transfer and radiative energy harvesting, opto-mechanics, electromagnetic metamaterials and metasurfaces, thermo-optics, and light-matter interactions in nanoscale devices and materials.

Ognjen's research with photonic and optical materials explores how light interacts with small objects on the nanoscale. At such small scales, the optical response of an object is dictated by both its intrinsic material composition as well as its geometrical shape. This combination enables the synthesis of artificial materials with complex optical functionality not found in natural materials. His interest is in using such metamaterials and metasurfaces for a variety of applications on Earth as well as in space, from efficient energy conversion and waste heat harvesting, to multifunctional yet lightweight materials for novel spacecraft designs, and even utilization of light for propulsion in space.

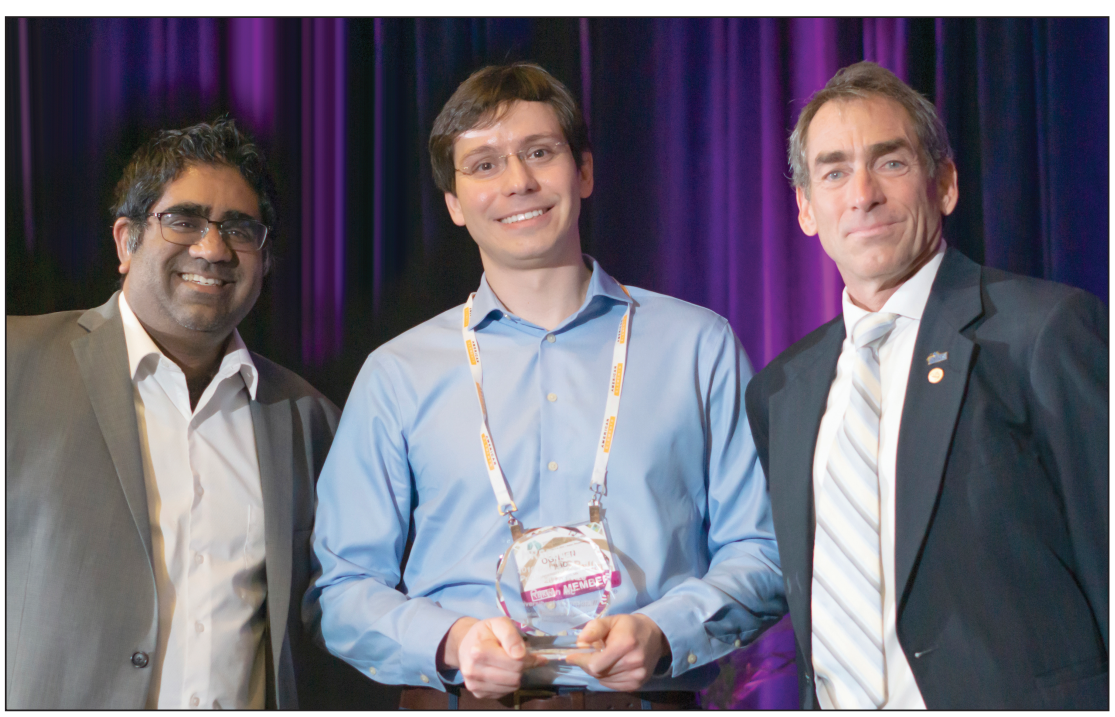

Ognjen llic receives the MRS Bulletin Postdoctoral Publication Prize from 2019 MRS President Michael R. Fitzsimmons (right) and MRS Awards Committee Co-chair Suveen N. Mathaudhu (left) at the 2019 MRS Fall Meeting.

In addition to starting his research group at the University of Minnesota, Ognjen teaches a mechanical measurements laboratory course for upperclassmen in multidisciplinary engineering. The course emphasizes written and oral communications; students produce written assignments, reports, and presentations. This teaches a variety of skills toward science communication by distilling information down to something that their peers could understand.

Ognjen's initial interest in writing and science communication started with a desire to relate the problems that he works on to areas and applications of interest that the public would care about- to show the relevance.

"Social media has opened a new playing field [for science communication] for reaching out," said Ognjen. With his new research group, he wants to ensure their presence is "representative of what they are doing and that they are reaching out in the right ways by rising above a lot of the technical language of papers to engage a broad audience."

To accomplish this, Ognjen has worked with university news offices to produce pieces and highlights of his work that are accessible to the general public. He also enjoys visiting undergraduate institutions and giving talks to engage a younger audience in the hopes of inspiring future scientists, engineers, and decision makers.

Regarding advice to new writers, he recommends being passionate about whatever you do and to engage in opportunities.

"Global communities are now somewhere we can reach through social media. In terms of writing, keep to the core message. Always be cognizant of the type of language needed for the general public and nonexpert. Always be conscious of your target audience in your writing."

The prize consists of a $\$ 2,000$ cash award, a profile published in MRS Bulletin, a complimentary one-year membership in the Materials Research Society, and an invitation to publish in MRS Bulletin.

MRS acknowledges the Jiang Family Foundation and MTI Corporation for their generous contributions to support the Postdoctoral Publication Prize. 